\title{
The Effectiveness of The Body of Knowledge Process in The Startup $\sim$ Analysis of Efficiency by Applying Startup Management Body of Knowledge (SUBOK) Guide
}

\author{
Hitoshi Hirai ${ }^{1, *}$, Shogo Kamei ${ }^{2}$, Masakazu Ohashi ${ }^{3}$ \\ ${ }^{1}$ Graduate School of Policy Studies, Chuo University, Tokyo, Japan \\ ${ }_{2}^{2}$ Advanced Institute of Industrial Technology, Tokyo, Japan \\ ${ }^{3}$ Graduate School of Policy Studies, Chuo University, Tokyo, Japan \\ a17.hb3j@g.chuo-u.ac.jp* \\ * corresponding author
}

(Received June 6, 2021 Revised June 13, 2021 Accepted June 25, 2021, Available online July 1, 2021)

\begin{abstract}
Entrepreneurs who create new businesses using innovative products and services that leverage the basic technologies of the 4th industrial revolution such as AI, IoT, Big Data and others technologies led by Germany and the United States have also emerged in Asia. Due to the diversification of consumer needs in recent years and the need for customer experience management to increase royalties, etc., the development cycle of new products and unique services tends to be shortened and how quickly they can be provided, which is a major problem. success factor. Meanwhile, in order to grow a business sustainably, it is also important to develop the right business strategy, build a governance structure, create value, and raise funds. In this thesis, we consider a startup as a project and describe the usefulness of implementing the Startup Body of Knowledge (SUBOK) Guide which systematizes the process to realize a startup quickly and reliably. In particular, we hypothesize that it is important to balance economic value and social value for startups, and consider the results of the implementation and analysis of the questionnaire.
\end{abstract}

Keywords: startups; Entrepreneurs; PMBOK; SUBOK Guide; CSV;

\section{Introduction}

\subsection{Background of the study}

In Japan where the population is declining and the birthrate is declining and the aging population is increasing, the working population is also declining, and markets are maturing, economic growth is sluggish and there is a sense of stagnation (Figure 1). Under these circumstances, entrepreneurs creating new businesses have emerged also in Asia including Japan using innovative products and services utilizing new technologies of the 4th industrial revolution such as AI technology, IoT, big data.

Entrepreneurship promotes industrial metabolism, and it is the driving force for economic growth. LVMises (1966) says, in "Human Action", "In a changing economy, the inherent tendency of profit and loss to disappear is always extraordinary, only the occurrence of new changes causes another revaluation." Entrepreneurship demonstrates that it contributes to economic growth and development and has mechanisms to move producers from the current economic situation to higher profit opportunities. 


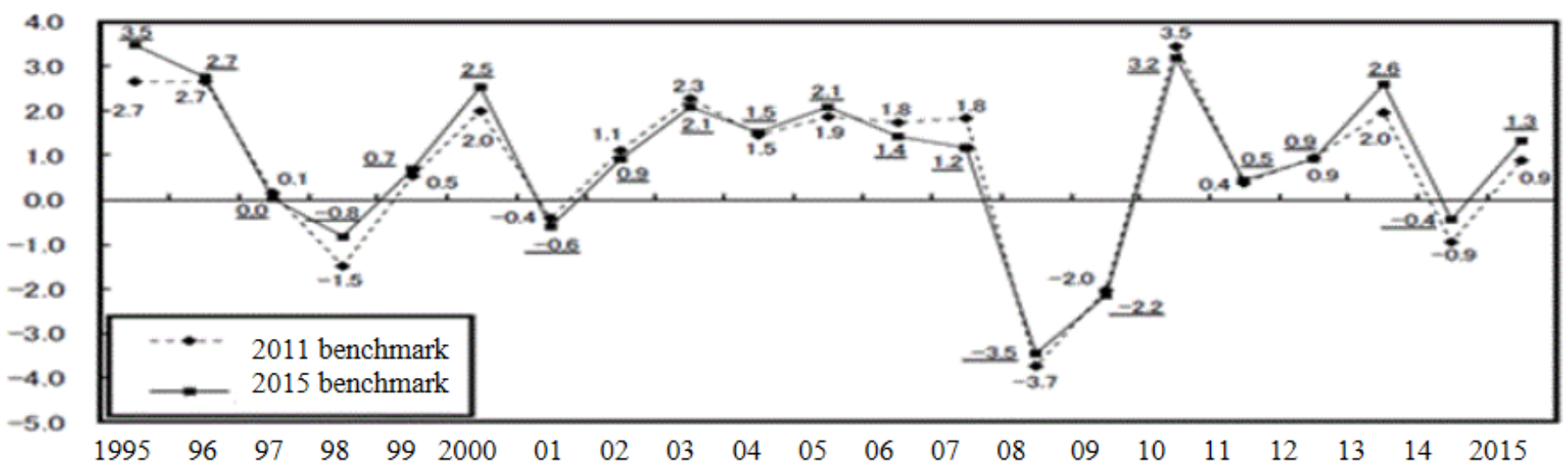

Figures. 1. Real GDP growth rate in Japan

\subsection{Purpose of the study}

In order to increase the startup success rate and sustainable growth of the company starting the business, when starting, it is important not only to develop innovative products and services, but also to manage activities such as developing business strategies, improving governance. structure, fundraising is also necessary. The purpose of this study was to examine the results of a questionnaire analysis on motivation to start and what is important when starting. Moreover, since a startup can be considered as a project, it is possible to use PMBOK ${ }^{\circledR}$ Guide [1] which is a project management knowledge system. However, because PMBOK ${ }^{\circledR}$ Guide does not assume only startup, there are management processes that are not covered by PMBOK ${ }^{\circledR}$ Guide. Therefore, in this study, the aim is to systematize project knowledge at startup, from the point of view of efficiency and usability through the implementation of the Start-Up Management Body of Knowledge (SUBOK) Guide [2].

\subsection{Current status of startup}

\subsubsection{Global Entrepreneurship Monitor (GEM)}

The Global Entrepreneurship Monitor (GEM) is mainly based on the hypothesis that the economic development of the country is closely related to the entrepreneurial activity, mainly by Babson Collegein the United States and the University of London in the UK, Starting from 10 countries including Japan in 1999, we are carrying out empirical research aiming to clarify three points, and in 2015 we are expanding to international comparative study of 61 countries.

- Is there a difference in entrepreneurial activities by country?

- Is there relevance to economic activity and entrepreneurial activity?

- What are the factors that create differences in entrepreneurial activities?

The main research objectives of GEM are to elucidate the growth process of venture companies, understand the factors that activate entrepreneurial activity, and then quantitatively measure the influence on national economic growth, competitiveness, employment, etc. It's in that. Ultimately, it aims at making policy recommendations for revitalizing the national economy, and mainly makes the following asa specific research subject.

- How the level of entrepreneurial activity differs among countries

- What policies and policies will enhance the level of national entrepreneurial activity

- What is the relationship between entrepreneurial activity and economic growth

\subsubsection{Total Early-Stage Entrepreneurial Activity (TEA)}

One of the important goals of GEM is to create reliable indicators to compare the level of entrepreneurial activity in each country. Therefore, they developed the "Total Early-Stage Entrepreneurial Activity (TEA)" scale as an indicator of active entrepreneurial activity in each country. 
In GEM, the total "birthday" and "childhood" defined as in Figure 2 is taken as the entrepreneurial activity of each country, and the proportion (\%) of these entrepreneurs in the adult population is TEA. "Birthday" is a person who is preparing to start a new business regardless of independence or internal company and who has not received or received a salary if the term is less than 3 months, "childhood" is a manager who already owns the company and is defined as someone who receive remuneration from the project for more than 3 months but less than 3.5 years.

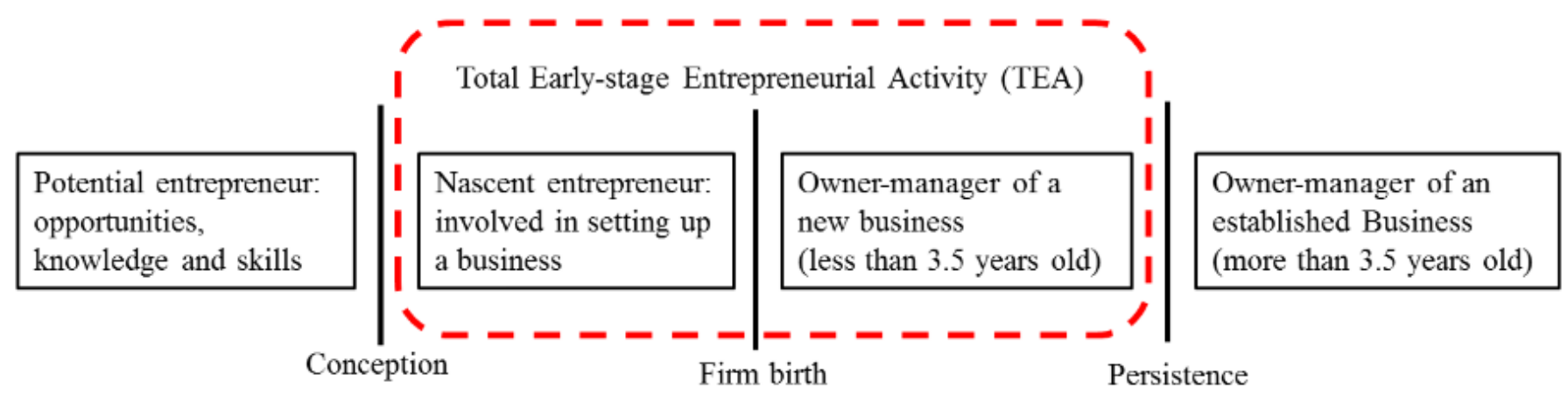

Numbers. 2. The Object of the Initial Stage of Total Entrepreneurial Activities (TEA)

\subsubsection{Current status of each country's startup}

According to the "Survey on entrepreneurship and venture support in 2015" compiled by the Nomura Research Institute as a survey conducted by the Ministry of Economy, Trade and Industry on the results of the GEM survey, Total Early-Stage Entrepreneurial Activity (TEA) "is very low in Japan (Figure 3 ), it cannot be said that the company's activities are inactive. In Japan, the entrepreneurial environment has not been adequate due to its stability orientation and the difficulty of re-challenging the assumption of a lifetime job so far. In recent years, measures such as the creation of new businesses, policies for establishment/promotion of business growth, improvement of the tax system/loan system, promotion of entrepreneurship education, etc. were implemented in several ministries and institutions, the entrepreneurial environment has increased Entrepreneurship by not only young people but also early retirees, retirees, women entrepreneurs are being activated.

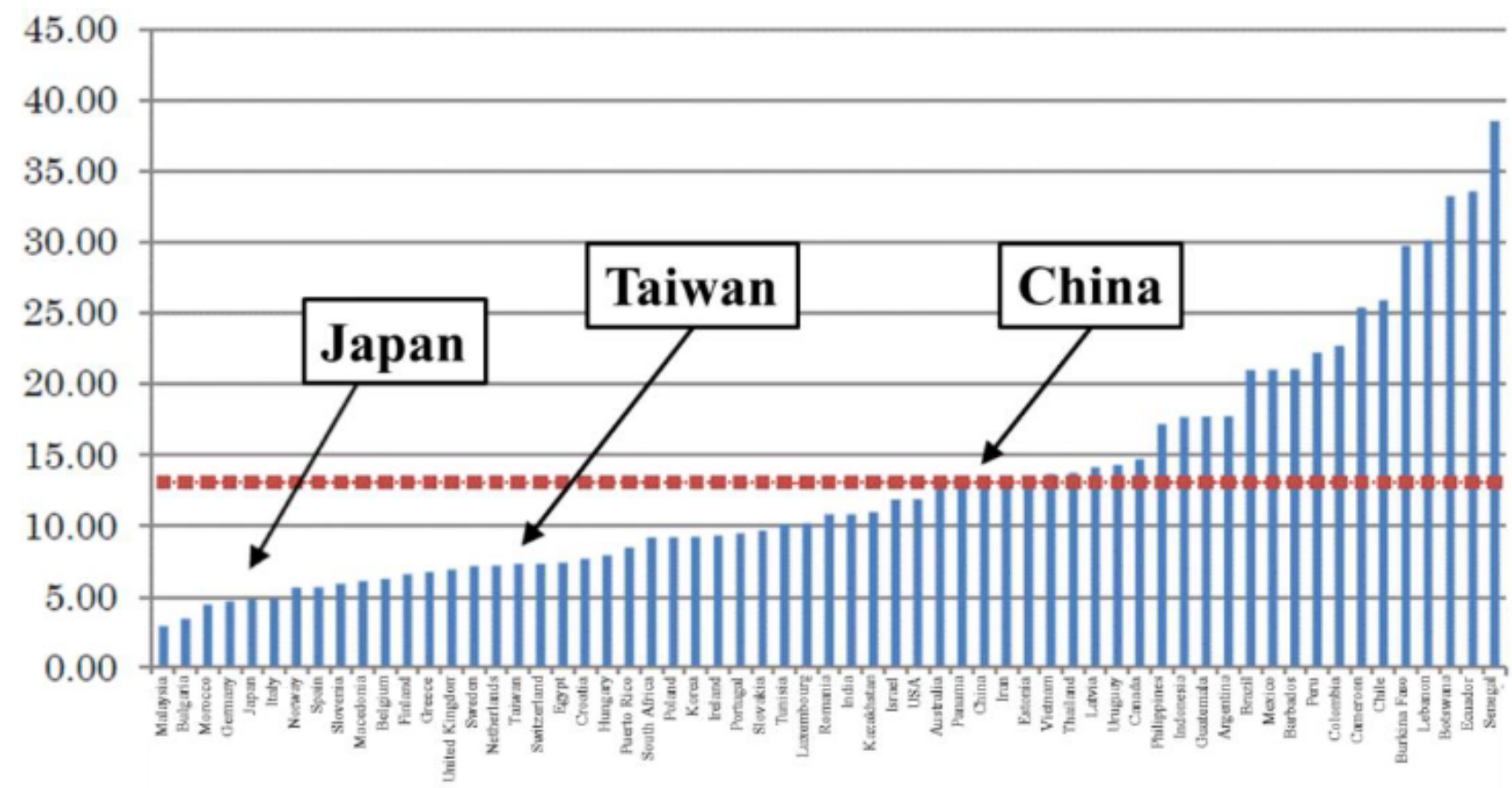

Figures. 3. "Total Early-Stage Entrepreneurial Activity (TEA)" in each country 


\section{Literature Review}

Startup Means starting a new business, but by not only starting a business but also developing a new business model, providing innovative products and services, it will be possible to grow in a short period of time and get great profit It can be regarded as aiming activity. In a narrow sense, the startup often refers to "a company aiming at getting rich with money by selling", but in a broad sense it includes "companies that are not aiming for sale, but are growing rapidly (trying to do)". In order to startup, it is necessary to create value by providing products that have never existed or services based on innovative business models. In the field of startup in 21 st Century, many people used the Internet etc. In recent years, under the 4th industrial revolution, Entrepreneurs are appearing and trying to "startup" by creating new business using AI technology and big data.

In addition, Mr. EricLease advocated in 2008, Lean Startup is a management method in the startup of a new business, repeatedly constructing and verifying hypotheses in short cycles, gradually improving products and services, optimizing needs is a method to search for. In recent years where the market needs are changing drastically, the plan formulated for startup cannot be executed as planned, and due to the cash flow etc. There are many cases of "closing", and the survival rate of startup companies is extremely low. Therefore, by repeatedly making small failures and verifications during the startup preparation period before starting "startup" or just after starting up, by gradually bringing closer to the products and services actually requested by the user or the market, it is a way of thinking to carry out realisticstartup.As a previous study on startup, we describe the Start-Up management Body of Knowledge (SUBOK) Guide, Creating Shared Value (CSV), Benefit Realization Management (BRM), and the current status of startup in Japan.

\subsection{Start-Up Management Body of Knowledge (SUBOK) Guide}

To get started, it is important to provide innovative products and services, but to build it as a business, it is necessary to have a clear strategy and minimum management as a company. Therefore, there is a Start-Up Management Knowledge Body Guide (SUBOK) which considers a startup as a project and summarizes the necessary management. SUBOKGuide is a systematic knowledge of projects at startup that is not covered by PMBOK® which is a guide to project management knowledge, and management processes on startup strategy, governance, benefits, finance, organization, etc., by Master Program in Information Systems Architecture, Institute of Technology Advanced Industries (AIIT).

As shown in Figure 4, the scope of the startup knowledge guide (SUBOK) is to build a business from entrepreneurial vision and mission, strategy formulation and governance, etc., to sustainable value creation, and based on the idea of repeatedly executing processes over that period. 


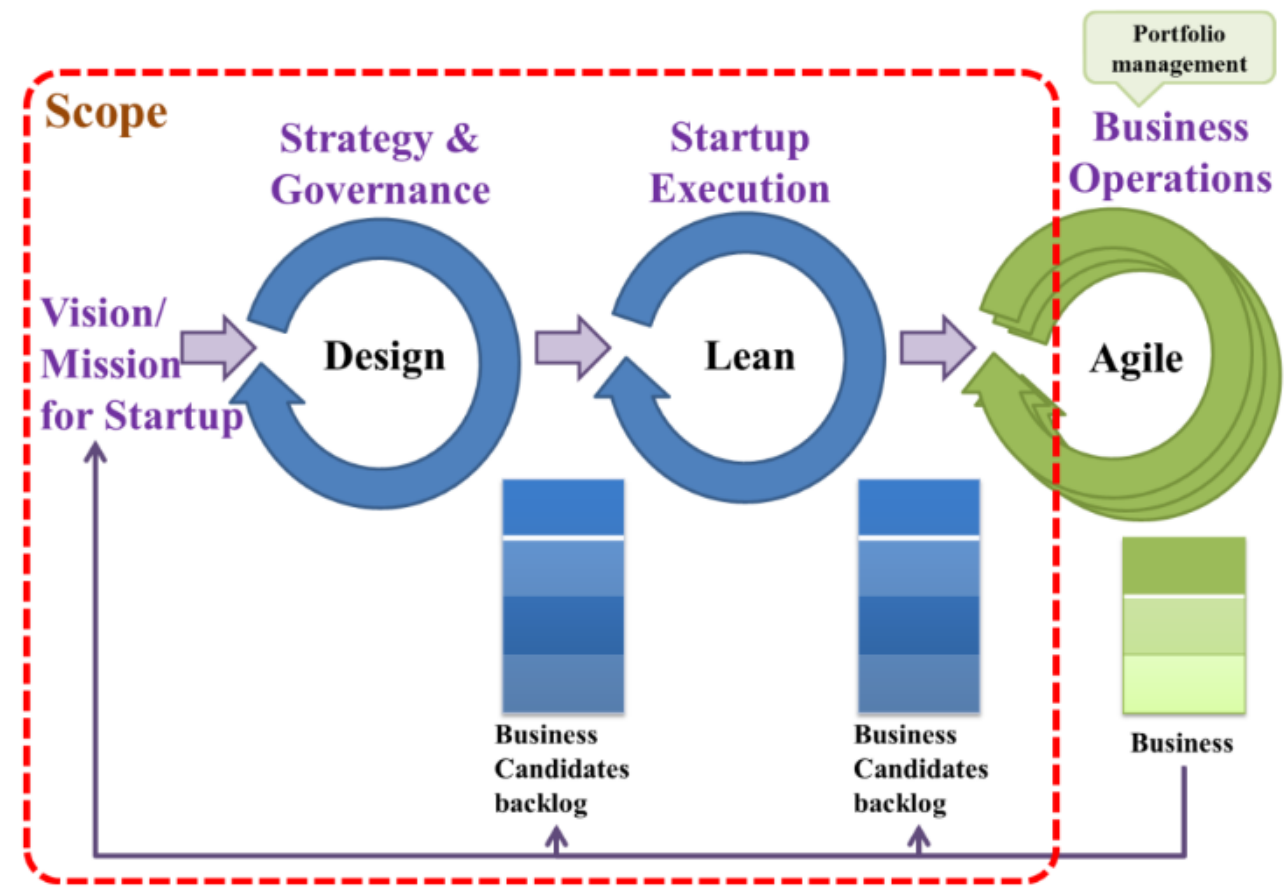

Figures. 4. Scope of the Start-Up Management Body Of Knowledge (SUBOK) Guide 
As a management process that is necessary when a startup is regarded as a project activity, the Start-Up management Body of Knowledge defines 30 management processes for each of the following six knowledge areas (Figure 5).

- Startup Strategy Management

- Startup Governance Management

- Startup Benefit Management

- Startup Execution Integrated Management

- Startup Finance Management

- Startup Organization Management

\begin{tabular}{|c|c|c|c|c|c|}
\hline \multirow[b]{2}{*}{ Knowledge Areas } & \multicolumn{5}{|c|}{ Startup Management Process Groups } \\
\hline & Initiating Process Group & Phnnning Process Group & Executing Process Group & \begin{tabular}{|c} 
Monitoring \& Controlling \\
Process Group
\end{tabular} & Closing Process Group \\
\hline $\begin{array}{l}\text { Startup Strategic } \\
\text { Managemnet }\end{array}$ & $\begin{array}{l}\text { Founder's vision clearly } \\
\text { stated } \\
\text { Mission statement creation } \\
\text { Business Discovery and } \\
\text { Domain Configuration }\end{array}$ & $\begin{array}{l}\text { - Startup strategy plan } \\
\text { formulation } \\
\text { - Roadmap formulation } \\
\text { - Performance management } \\
\text { plan }\end{array}$ & & - Strategic Change Evaluation & \\
\hline $\begin{array}{l}\text { Sutartup Governance } \\
\text { Managemnet }\end{array}$ & $\begin{array}{l}\text { Formulation of Code of } \\
\text { Conduct }\end{array}$ & $\begin{array}{l}\text { - Governance management } \\
\text { plan } \\
\text { - Internal control system } \\
\text { design } \\
\text { - Compliance standard setting } \\
\text { - CSR policy formulation }\end{array}$ & $\begin{array}{l}\text { - Governance leadership } \\
\text { management }\end{array}$ & $\begin{array}{l}\text { - Monitoring compliance with } \\
\text { governance Control }\end{array}$ & \\
\hline $\begin{array}{l}\text { Startup Integration } \\
\text { Managemnet }\end{array}$ & & & $\begin{array}{l}\text { Command execution of } \\
\text { startup management }\end{array}$ & $\begin{array}{l}\text { - Monitor startup execution } \\
\text { Control } \\
\text { Change integration }\end{array}$ & $\begin{array}{l}\text { - EXIT of startup execution } \\
\text { cycle }\end{array}$ \\
\hline $\begin{array}{l}\text { Startup Benefit } \\
\text { Managemnet }\end{array}$ & & - Definition of value & $\begin{array}{l}\text { - Realization and acquisition } \\
\text { of value } \\
\text { - Capitalization of value }\end{array}$ & - Evaluation of value & \\
\hline $\begin{array}{l}\text { Startup Finance } \\
\text { Managemnet }\end{array}$ & & $\begin{array}{l}\text { - Creation of executable } \\
\text { finance structure }\end{array}$ & - Financing & - Control of financing & - Funding finished \\
\hline $\begin{array}{l}\text { Startup Organization } \\
\text { Managemnet }\end{array}$ & & - Startup organization design & $\begin{array}{l}\text { - Organization of startup team } \\
\text { - Securing human resources } \\
\text { - Operation of startup } \\
\text { organization }\end{array}$ & & \\
\hline
\end{tabular}

Figures. 5. Startup Management Processes

In this section, we extract the processes and tasks in which project management methods can be applied from among the management processes of the six knowledge areas defined in the Start-Up Management Knowledge Body (SUBOK) Guide, and the tools and techniques referred to in this guide also consider utilization methods included.

In startups leveraging AI technology and IoT technology under the 4th Industrial Revolution, we introduce products and services to a new market called Blue Ocean, and respond to technology that is more advanced than the year of the dog. We have to challenge businesses with such high uncertainty. Therefore, it is important to verify the validity of each management process and adapt it to the changing business environment by measuring performance and analyzing data through startup management activities and providing feedback.

Therefore, it is necessary to repeatedly execute the tasks to be executed by the project management method in short units of time called iterations, measure each iteration of execution time, confirm productivity which is called speed, and provide feedback on the activity itself. The one iteration period is carried out in about 2 to 3 weeks, and every week, at a fixed time, we review with the KPT3dst method. and leads to increased activity. Also, at the final stage of each iteration, it is necessary to hold an iteration review meeting and the entrepreneur himself must confirm the deliverables. 
Hereinafter, with reference to the research results at the Sakamori laboratory of Advanced Institute of Industrial Technology (AIIT), we outline the management process for each knowledge area of the Start-Up management Body of Knowledge (SUBOK) Guide.

\subsubsection{Startup Strategy Management}

The startup strategy management consists of seven processes to formulate a startup strategy to fulfill the vision and fulfill the mission as well as formulate a strategy-based roadmap.

- The founder's vision is clearly stated

- Mission statement creation

- Business Discovery and Domain Management

- Startup strategy plan formulation

- Roadmap Formulation

- Performance management plan

- Strategic Change Evaluation

In developing a startup strategy, you can refer to the theory of management strategy, but in a startup project that uses new technologies such as AI technology, it is possible to become a business with higher uncertainty than the implementation of existing technologies, and startup strategy and roadmap formulation In the process, review may be necessary and it is important to adapt quickly.

\subsubsection{Startup Strategy Management}

Startup governance management is an important management for sustainable company growth after entrepreneurship. This knowledge area consists of 7 processes.

- Formulation of the code of ethics

- Governance management plan

- Internal control system design

- Compliance standard setting

- CSR policy formulation

- Governance leadership and management

- Monitor and control governance compliance status

When starting out, it is important to formulate an innovative business strategy, secure resources and pursue profits. However, because of the emphasis placed on them, governance management such as internal control and compliance is not enough after entrepreneurship, management collapse There are also many cases. In addition, by linking strategic management and benefits management, CSR policies can be positioned as a foothold for new business in the future and can be considered as a CSV strategy to increase business value. In other words, from the outset, in addition to defensive governance management, it is important to run and control in a balanced way with offensive governance management to increase the value of the company in the future.

\subsubsection{Startup Execution Integrated Management}

Startup execution The knowledge area of integrated management monitors and controls the execution of startup projects to realize startup projects and integrates changes that occur in the course of realizing the project toward value creation and concludes the execution cycle of the startup project This process consists of four processes.

- Startup execution command and execution · Management

- Startup execution monitoring and control

- Change integration

- EXIT startup execution cycle 
In the process of implementing a startup project according to the strategy, each process needs to be integrated into the strategy based on the value creation assessment criteria, and compare the differences with the strategy caused by changes in the external and internal environment. By making a change request to the strategic plan, we integrate the strategic plan. To realize a successful start-up business, it is necessary to integrate changes to the predictive type, namely the implementation of the strategic plan, and changes to the strategic plan, and adaptive management that refines the strategic plan to create and strengthen the required value.

\subsubsection{Startup Benefit Management}

The knowledge area of startup benefit management consists of four processes: identifying and defining value, realizing its value, capitalizing it, and evaluating its value.

- Definition of value

- Realization and acquisition of value

- Capitalization of value

- Evaluation of value

We cannot survive the organization unless we can properly manage the benefits (benefits) including finance, in any organization.

PMBOK ${ }^{\circledR}$ has a knowledge area on cost management, but revenue (income) is not stated. However, in the startup project, it is necessary to prepare a mechanism for managing the benefits earned by organizations in advance. Management of "value" acquired by organizations, including financial benefits. Since the value changes, the processes in this knowledge area will be subject to iterative review during the startup period.

\subsubsection{Startup Finance Management}

Startup finance management consists of four processes to raise funds necessary for starting a business.

- Creation of an executable finance structure

- Financing

- Fund procurement control

- Termination of funds procurement

In PMBOK®there is a description of project procurement management, but here is the process of procuring, utilizing and repaying funds at startup. In order to start up, finance management such as raising funds is an indispensable matter.

\subsubsection{Startup Organization Management}

Startup organization management consists of four processes to set up and operate an organization to realize a startup.

- Startup organization design

- Startup organization development

- Securing human resources

- Startup organization operation

A startup organization is an autonomous organization with authority and autonomy, and each member has a role and responsibility. Compared to regular corporate organizations, start-up organizations often start small. Therefore, each member often has multiple roles and responsibilities. In terms of securing human resources to become members of the organization from inside and outside the organization, it is better to hire employees in accordance with the organization's mission, governance, compliance standards and maintain diversity to build a highly productive organization. 


\subsection{Creating Shared Values (CSV)}

CSV (Creating Shared Value) was proposed as a concept to realize economic value (profit) and social value that the company pursued simultaneously by Michael E. Porter, etc. (2011). Creating Shared Value is a policy and its implementation to increase competitiveness while improving the economic and social conditions of the communities where the company operates. What needs to be emphasized in creating shared values is to clarify the relationship between social development and economic development and expand it, and it can also be said as "business ization of social problem solving". CSR (Corporate Social Responsibility) cannot lead to social change or innovation, but it also shows that CSV can bring them.

"Creating Shared Value" is an advanced concept that aims to pursue compliance and sustainability, with a medium to long term perspective, taking into account the social and economic situation. By conducting business activities that have social significance, we aim to continue to manage the company (Figure 6).

NestléS.A. is a representative company that uses CSV as its management strategy. NestléS.A.mapped to confirm the consistency of their material issues with the United Nations Sustainable Development Goals (SDGs) and has set a mandatory goal (commitment) consisting of 42 items by 2030. To measure CSV performance, KPIs (Key Performance Indicators) are set for each goal, and specific concrete action plans and progress situations are disclosed.

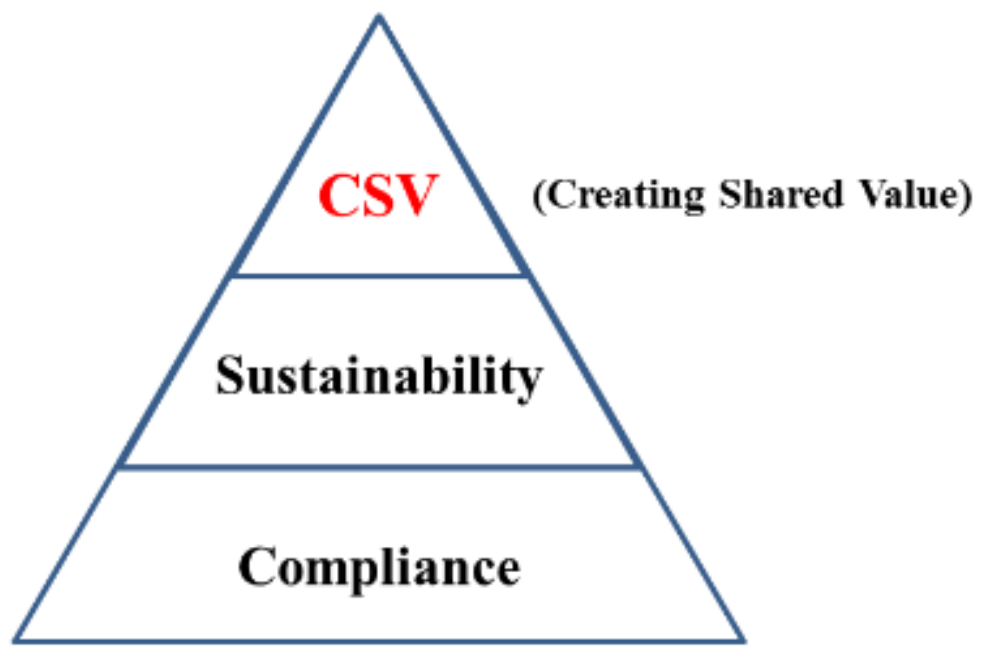

Figures. 6. Concept of CSV

\subsection{Benefit realization management (BRM)}

The Project Management Institute (PMI $\left.{ }^{\circledR}\right)$ announced Benefit Realization Management, based on project/program management, in 2016 (Figure 7). The realization of benefits from the transition to the utilization of new products, services and benefits is considered that management can be an effective tool in the value creation process in the early stages of startup. 


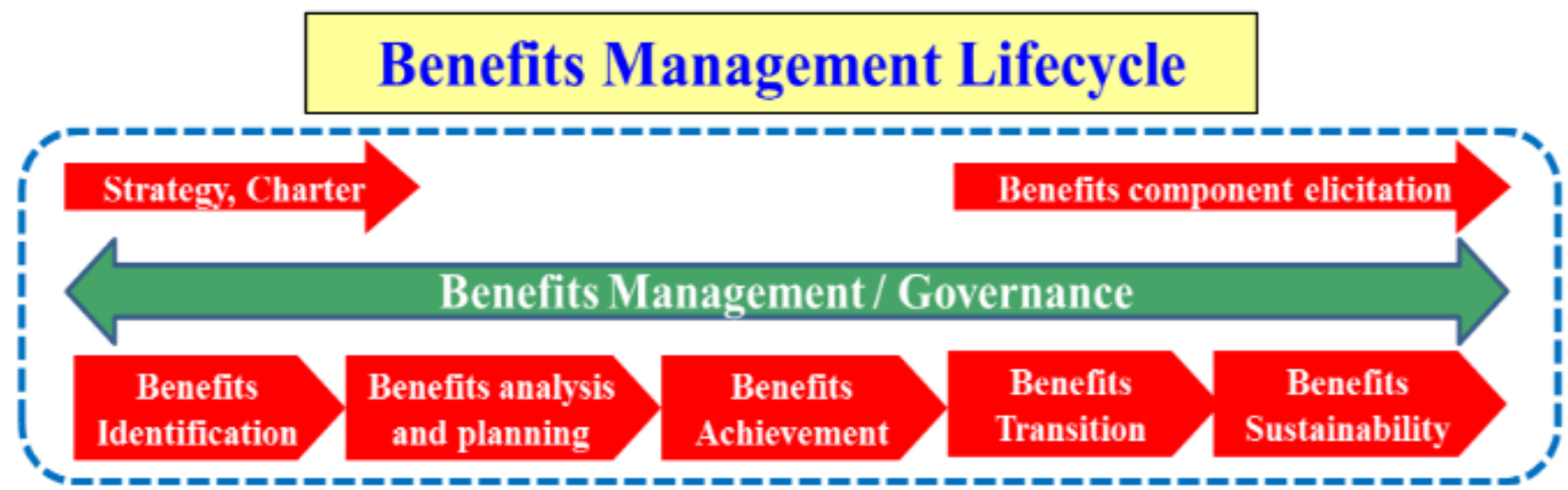

\section{Governance and Stakeholder management}

\begin{tabular}{|c|c|c|c|c|c|}
\hline \multicolumn{3}{|c|}{ Transition to utilization of new products, services and benefits } & \\
\hline $\begin{array}{c}\text { Operation } \\
\text { process }\end{array}$ & Training & $\begin{array}{c}\text { Testing, } \\
\text { Acceptance }\end{array}$ & $\begin{array}{c}\text { Configuration } \\
\text { management }\end{array}$ & $\begin{array}{c}\text { Service } \\
\text { management }\end{array}$ & $\begin{array}{c}\text { Assessment } \\
\text { Program / }\end{array}$ \\
\hline \begin{tabular}{c|c|c|c|} 
Vendor \\
service
\end{tabular} & $\begin{array}{c}\text { Human resource } / \\
\text { Financial management }\end{array}$ & $\begin{array}{c}\text { Risk } \\
\text { management }\end{array}$ & $\begin{array}{c}\text { Knowledge } \\
\text { management }\end{array}$ & $\begin{array}{c}\text { Project } \\
\text { Closure }\end{array}$ \\
\hline \multicolumn{4}{|c|}{ Abolish old useless elements* } \\
\hline
\end{tabular}

Figures. 7. Benefits Management Lifecycle

\subsection{Survival rate of Japanese companies}

According to the Small and Medium Enterprises White Paper (2011), the survival rate of newly founded companies is $70 \%$ after 10 years and $50 \%$ after 20 years (Figure 8), which is very low. This includes not only startups but also sustainable funding, securing high quality human resources, acquiring management knowledge, corporate governance, identifying when to quit, responding to environmental changes, creating sustainable value, Penetration of corporate philosophy, improving organizational performance, difficulty maintaining work environment etc. also considered a factor. 


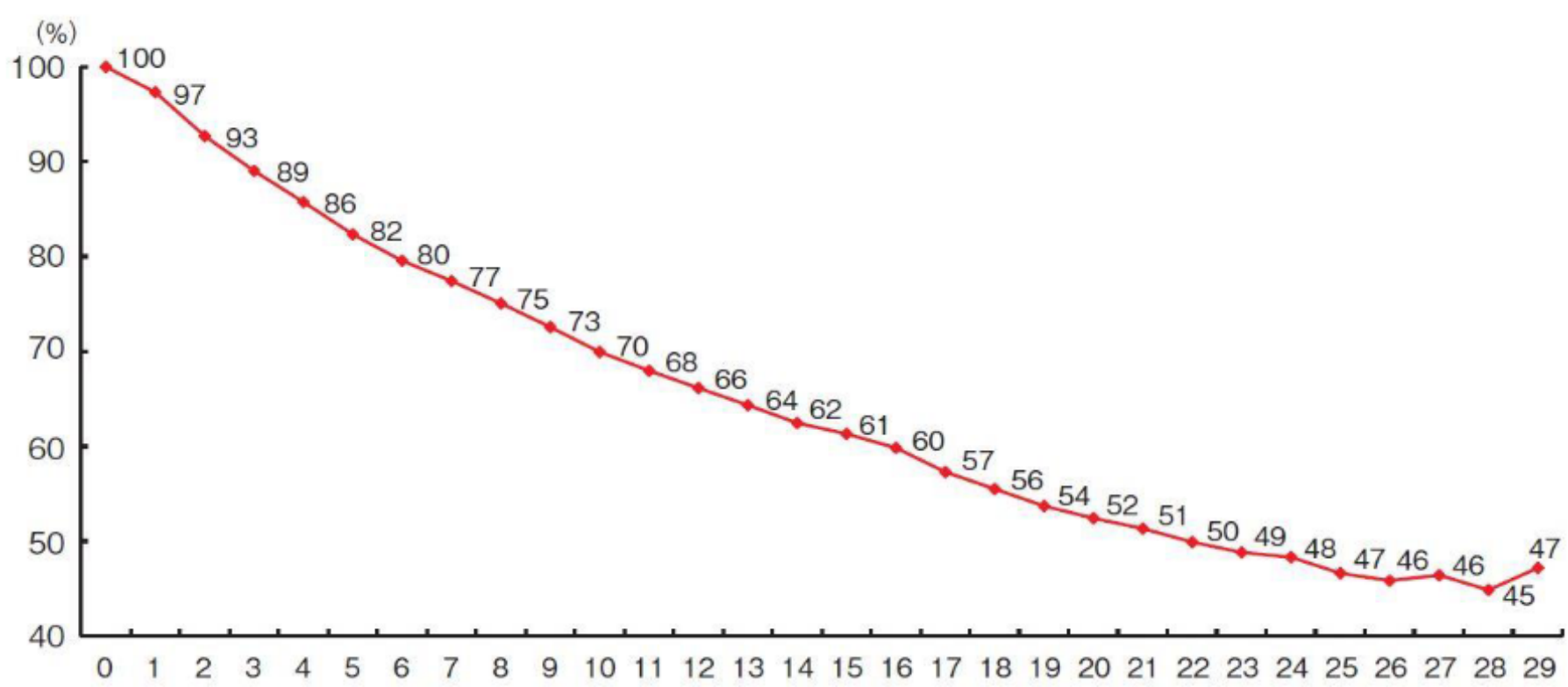

Figures. 8. Survival Rate of Japanese Companies (SME White Paper 2011)

According to the White Paper on SMEs (2017), the industries with a high rate of discontinuation are manufacturers and retailers (Figure 9), compared to the startup rate of enterprises.

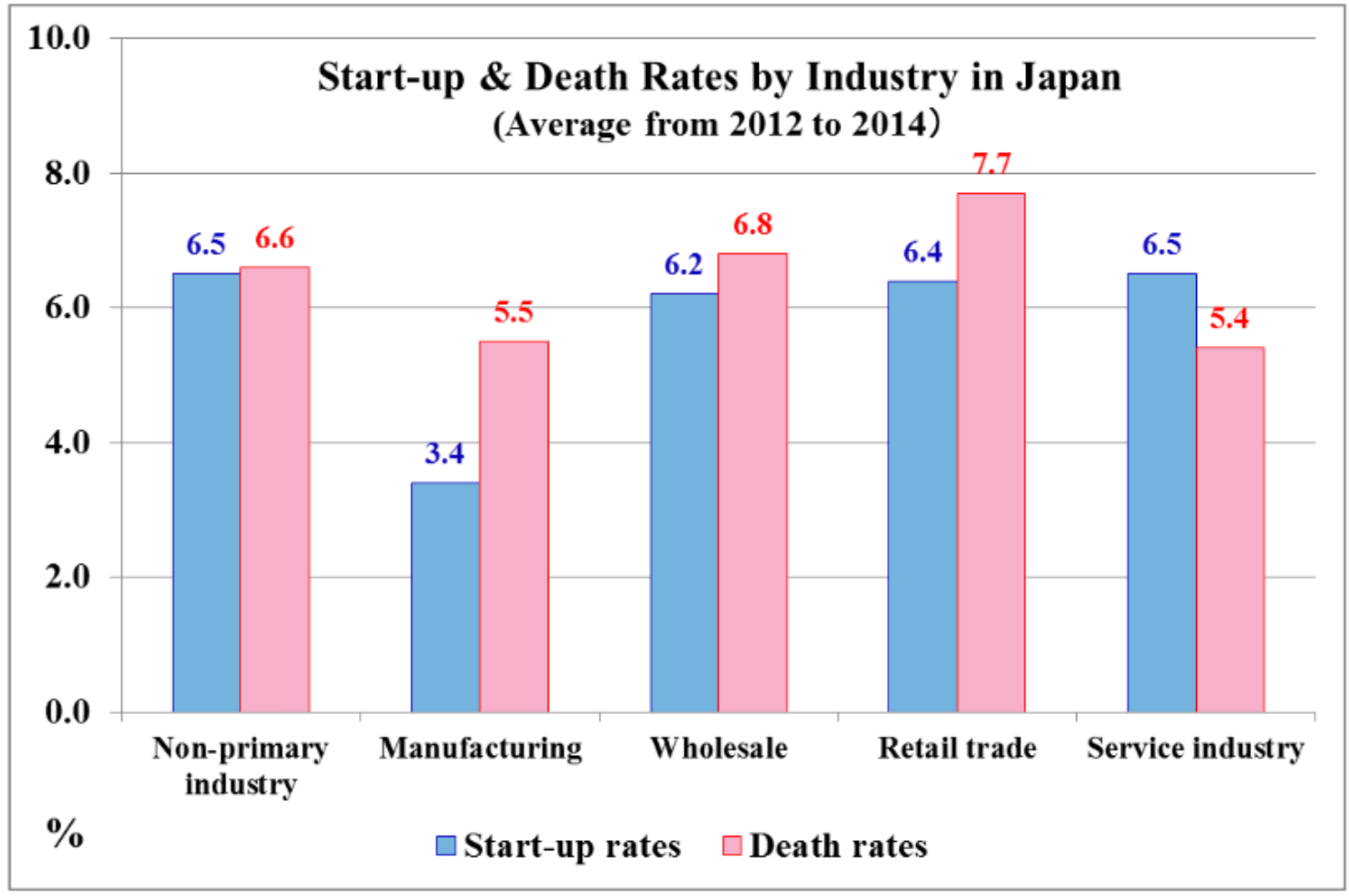

Figures. 9. Startup \& Death Rates By Industry in Japan

According to the White Paper and Statistical Information of Small and Medium Enterprises (according to Tokyo Shoko Research), there were about 60,000 companies in Japan that went bankrupt between 2011 and 2016, about $70 \%$ of the causes of bankruptcy were sluggish (Figure 10)). This explains how difficult it is to continue to provide value to the customers and consumers who offer products and services. 


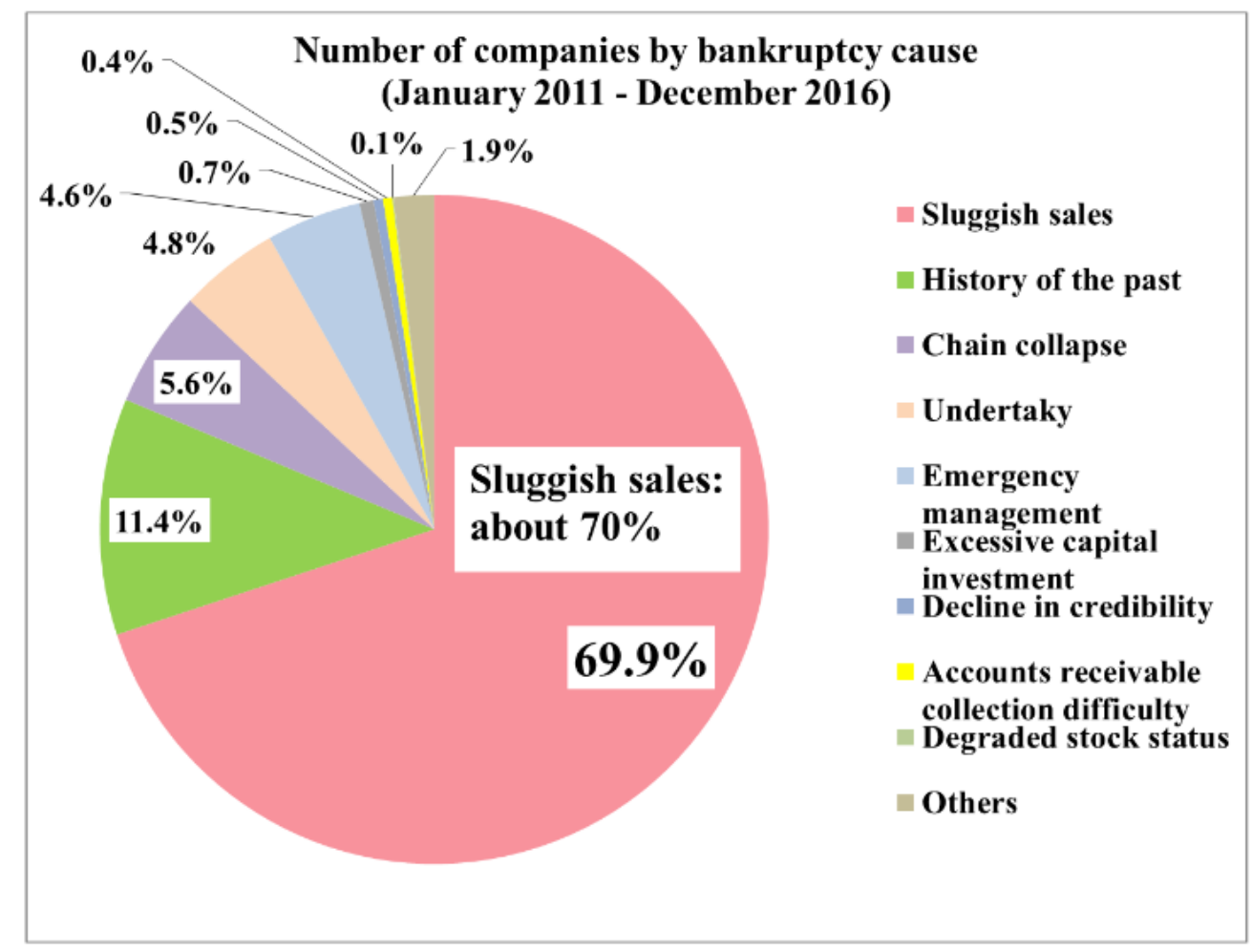

Figures. 10. Bankruptcy status of Japanese companies by cause

\section{Methodology}

\subsection{Consideration from previous research}

We have summarized the Body of Knowledge Guide (SUBOK) Start-Up management, Creating Shared Value (CSV), Benefit Realization Management (BRM) as an investigation of previous research. To increase the success rate of startups and sustainable growth, it is necessary to consider not only the economic value but also the social value from now on.

Japanese companies have a high affinity for the concept that emphasizes not only economic value but also social value in terms of corporate climate and historical cases and there are also cases that have been realized. Therefore, even if it is not a global company like Nestlé S.A., in the case of startups in lean, the possibility of a startup that is more effective by using CSV concepts and ways of thinking for the value creation process and realization of benefits in startups exists.

\subsection{Research Question}

What kind of management processes should be emphasized to increase the likelihood of startup success? Also, what values are needed to make a startup successful and drive sustainable growth? Furthermore, is there a management method for realizing these values?

With regard to this research question, we will consider it mainly through the following previous research.

- Management process Guide Body of Knowledge (SUBOK) Start-Up management

- The Concept of Creating Shared Value (CSV)

- Benefit Realization Management Framework (BRM) 


\subsection{Hypothesis}

To increase the chances of startup success for a fast-paced business such as the adoption of rapidly changing technologies, it is important to know what startups really need to emphasize and how to make the startup management process more efficient. The following hypothesis is established.

Hypothesis 1: To make a startup successful and drive sustainable growth, it is important to balance economic value and social value.

Hypothesis 2: To realize value at startup, the Start-Up Management Body of Knowledge (SUBOK) Guide is effective in management processes such as setting a clear vision/mission, developing business strategies and business plans, financing, etc.

\subsection{Method of verification}

\subsubsection{Questionnaire survey on startup}

We conducted questionnaires about startup-related experiences and startups, etc. about startup desires, motivations, goals, points to emphasize, etc., entrepreneurial motivation and management process from the startup preparation stage to the actual startup. Investigate awareness of the importance of.

\section{Hypothesis Verification}

To prove the hypothesis that the congruence of economic value and social value is important at start-up, we conducted a questionnaire on startups mainly for the community and graduate students, and received responses from 108 people. The questionnaire was conducted regardless of experienced startup or inexperienced person. The results of this experiment will be analyzed and discussed below.

\subsection{Questionnaire on startup}

\subsubsection{Target of the questionnaire}

The questionnaire on startup was conducted for the following social workers and graduate students, and 108 respondents got responses. The number of respondents by gender for each age group is shown in Figure 4-1. Among the respondents, the number of experienced startups was about $37 \%$ (Figure 12). 


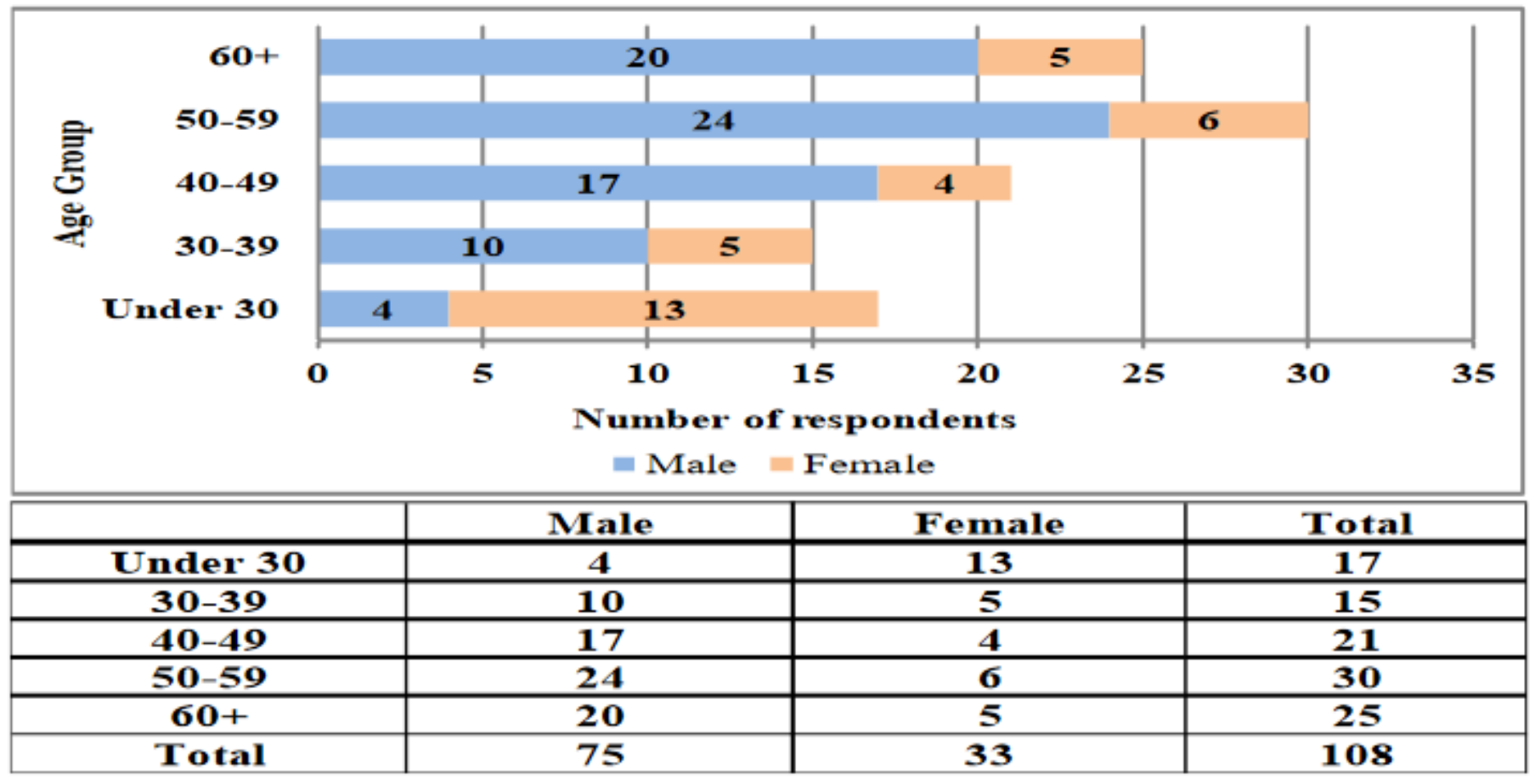

Figures. 11. Gender and age group of respondents in the questionnaire

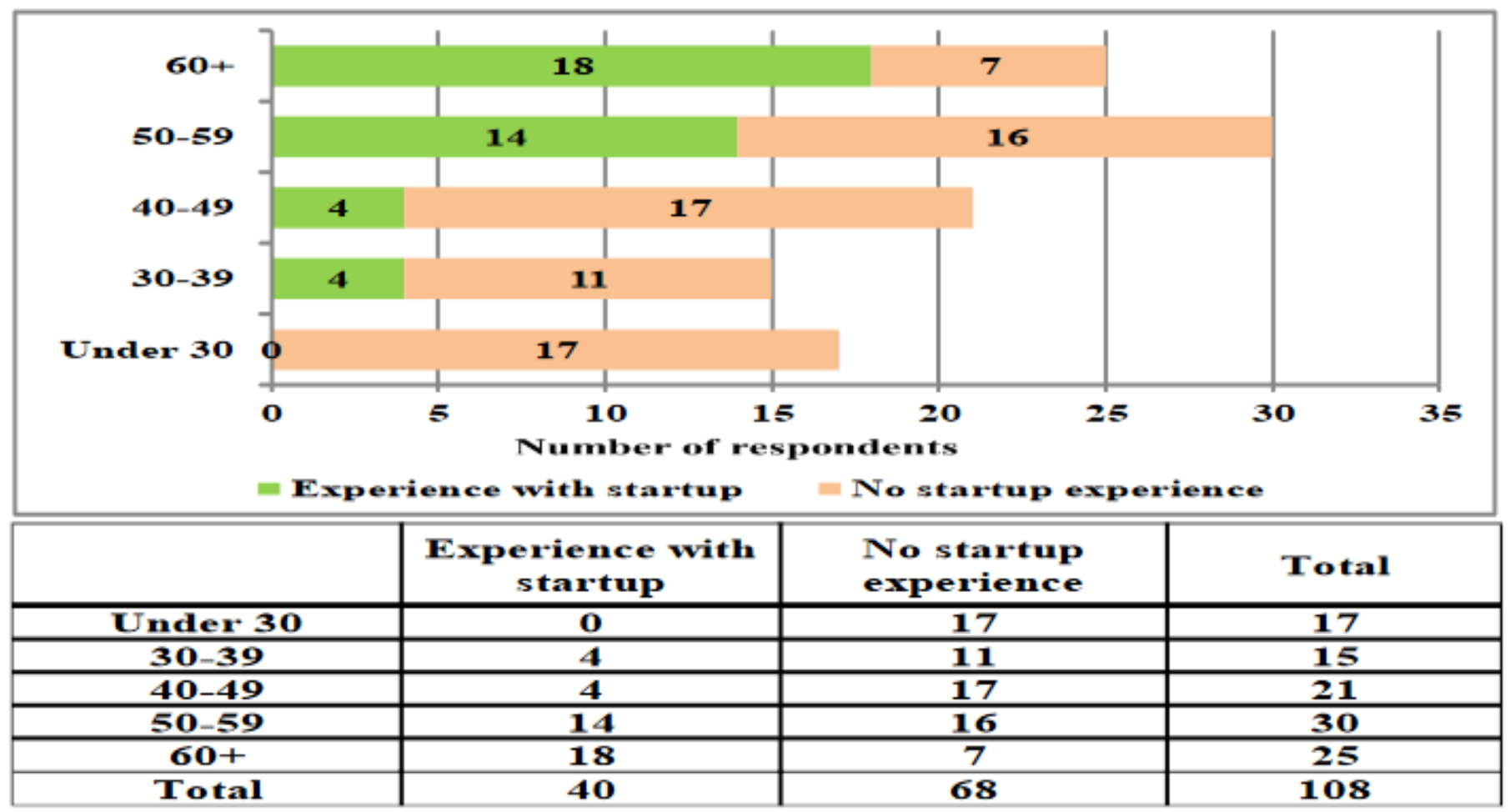

Figures. 12. Number of experienced startup persons of respondents in the questionnaire

Working people:

- Experienced startups, business owners

- Staff in preparation to start

- Students who completed the Chuo . University Graduate School of Policy Studies 
- Graduate student of Advanced Institute of Industrial Technology, AIIT (Postgraduate School of Industrial Technology)

- People who create new businesses and support startups: consultants like engineers, small business diagnostics, IT coordinators, etc.

- People who are currently unemployed, like housewives

Students:

- Graduate school students enrolled in Chuo University Graduate School of PolicyStudies

- Postgraduate students studying at the Advanced Institute of Industrial Technology, AIIT

- Graduate students and students currently enrolled in other faculties

\subsubsection{Questionnaire contents}

The contents of the questionnaire on startups are questions about the existence of entrepreneurship experience, entrepreneurial interests/experience, entrepreneurship goals, things that need to be emphasized in entrepreneurship, etc. The questionnaire sheet is shown in Figure 13.

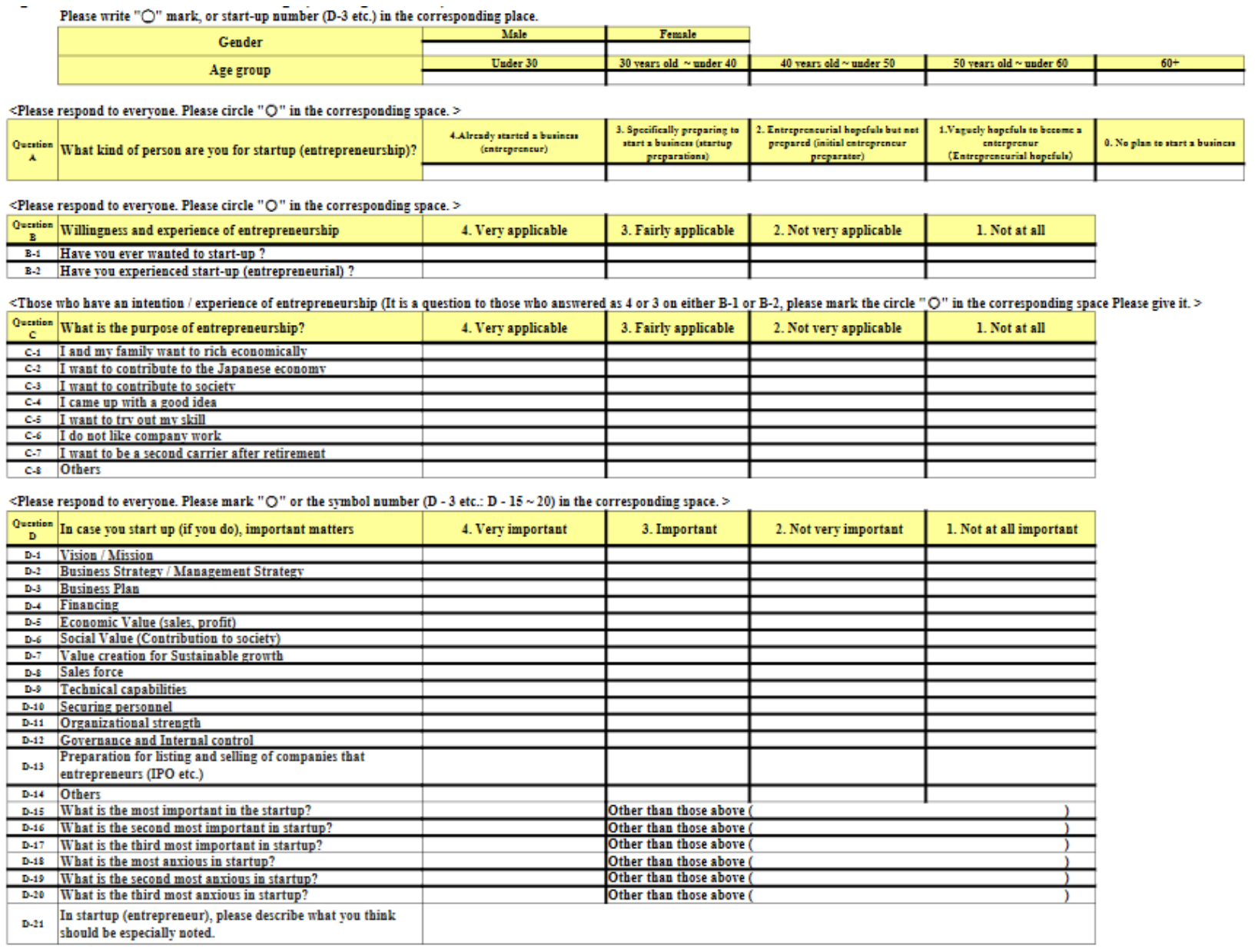

Figures. 13. Questions about Startup

\subsubsection{Questionnaire contents}

Of the 108 respondents who answered the questionnaire, there were 69 people who answered that they wanted to start so far (4 Very applicable or 3. Fairly applicable), which is $64 \%$. By age group, in their 50s before retirement, 25 out of 30 people $(83 \%)$ were the most frequent (Figure 14). Among the people who wanted to start so far, the motivation to try to get started was the most frequently answered, with 54 out of 69 people trying their skills, $78 \%$ (Figure 15). 
There are 47 people who want to contribute to society, $68 \%$, the second most frequent response. From these results, as a motive for starting, it turns out that more than two thirds of people consider contributing to society. Therefore, the creation of social value in startups is considered very important.

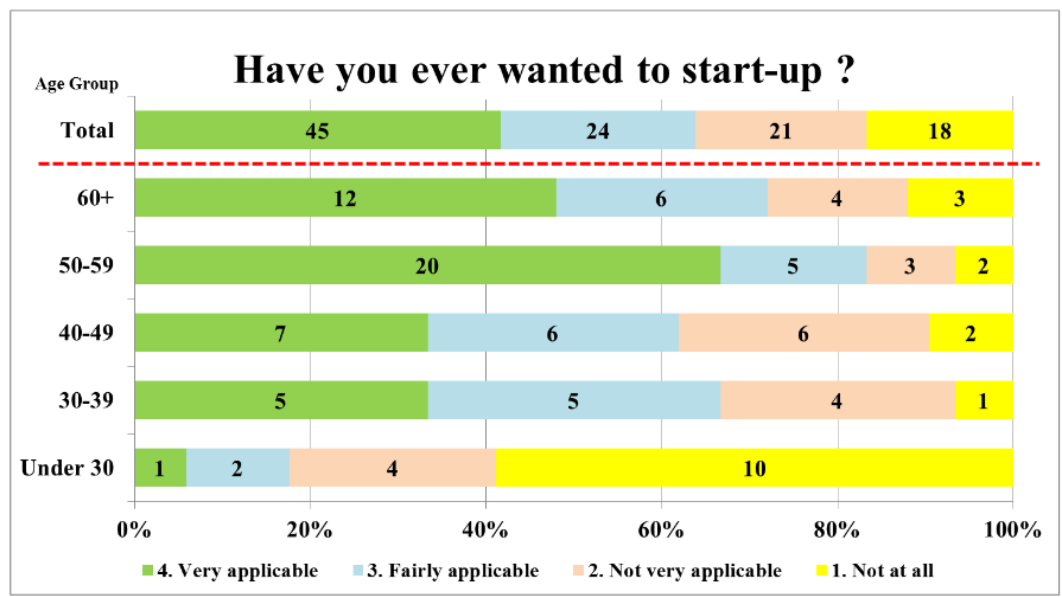

Figures. 14. Comparison of the number of people thinking of starting so far by age group

\section{What is the purpose of entrepreneurship? Among the respondents who have thought of starting up}

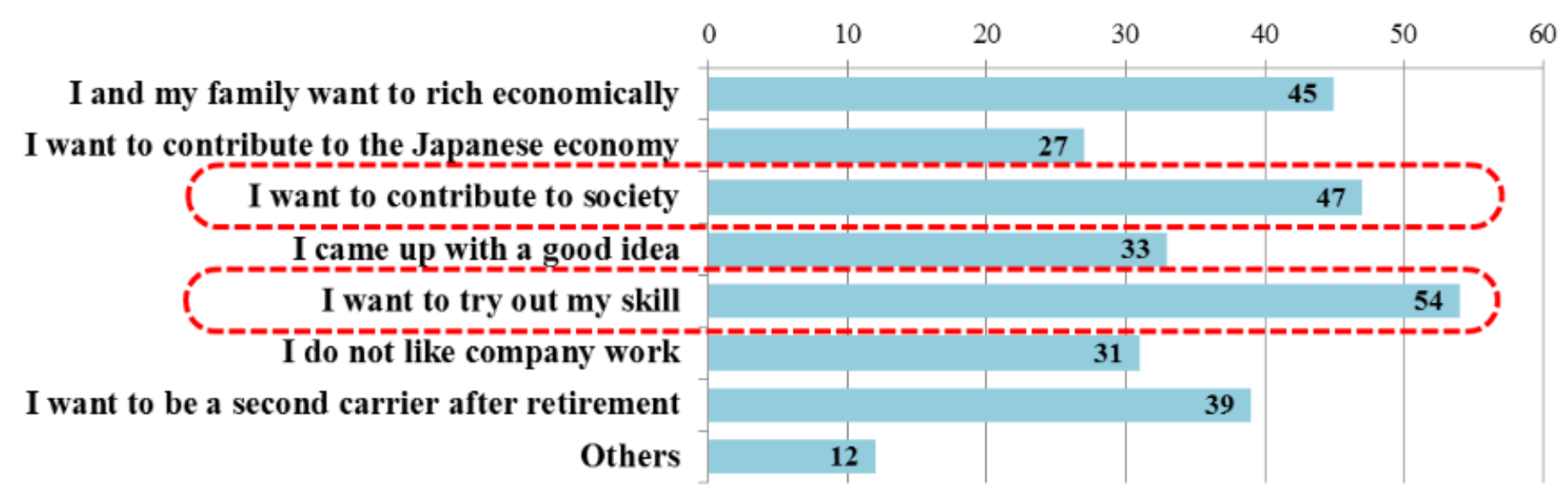

Number of respondents

Figures. 15. The purpose of entrepreneurship among the respondents who have thought of starting up

Furthermore, as a result of the question of the importance of the 13 subjects and the possible processes in starting, the number of people who answered Vision/Mission as very important was the largest, the second was Strategy/Business Management, the third was Business Plan (Figure 16). Also, the most important of these items is Vision/Mission, the second is Strategy/Business Management, the third is Social values (Contribution to society) (Figure 17). This means that awareness about social contributions is increasing, meaning that there are some people who are considering creating social value through startups.

On the other hand, at startup, Financing is the most frequent, the second is Economic Value (Sales, profit), and the third is Sales Force for questions about the most important issues (Figure 18). For startups, the most worrying thing is the uncertainty about procuring business funds at startup and ensuring sustainable sales profits, so it is important to strengthen the Sales force for that. 


\section{Important items at startup}

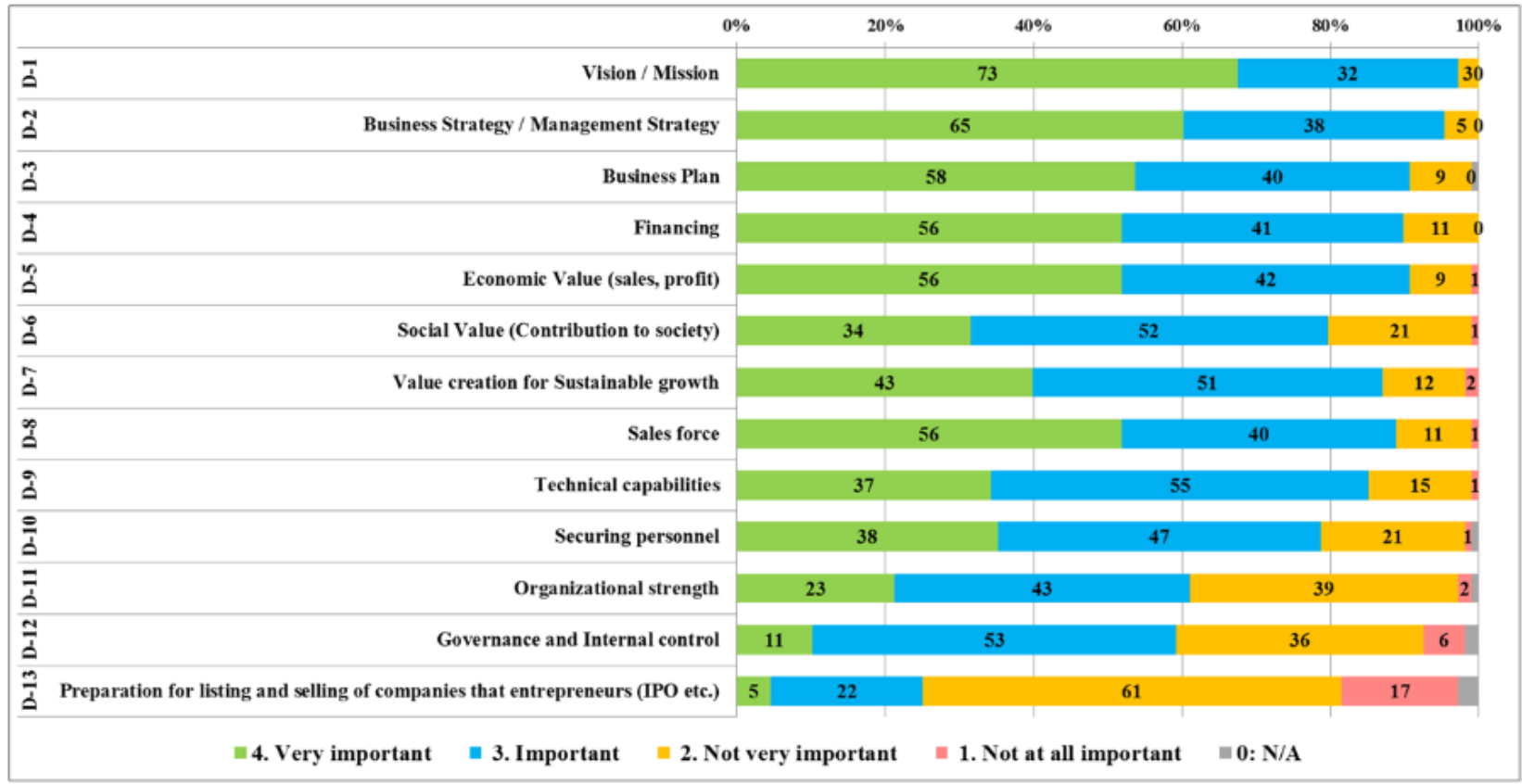

Figures. 16. The Important items at startup among all respondents

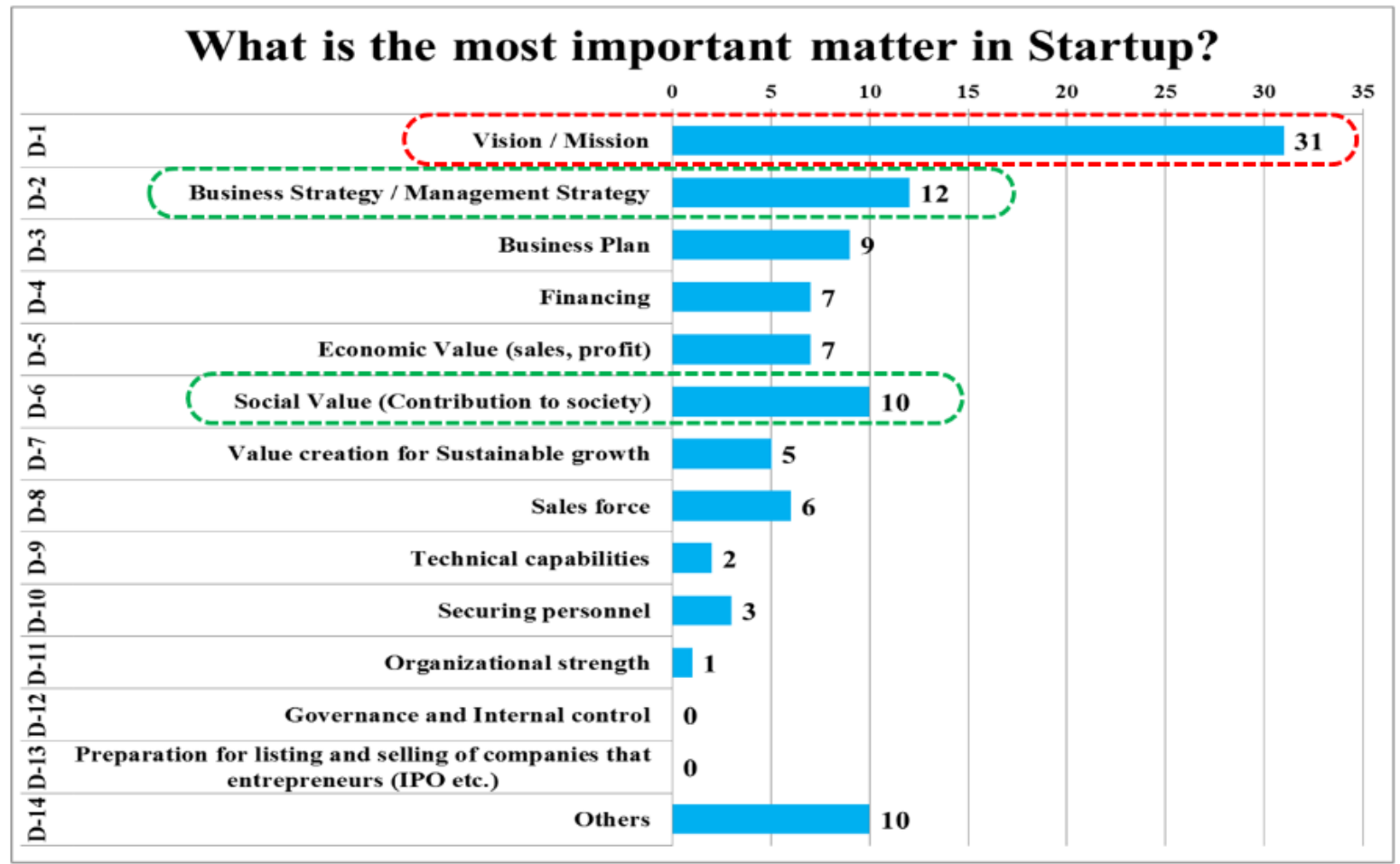

Figures. 17. What is the most important matter in Startup? 


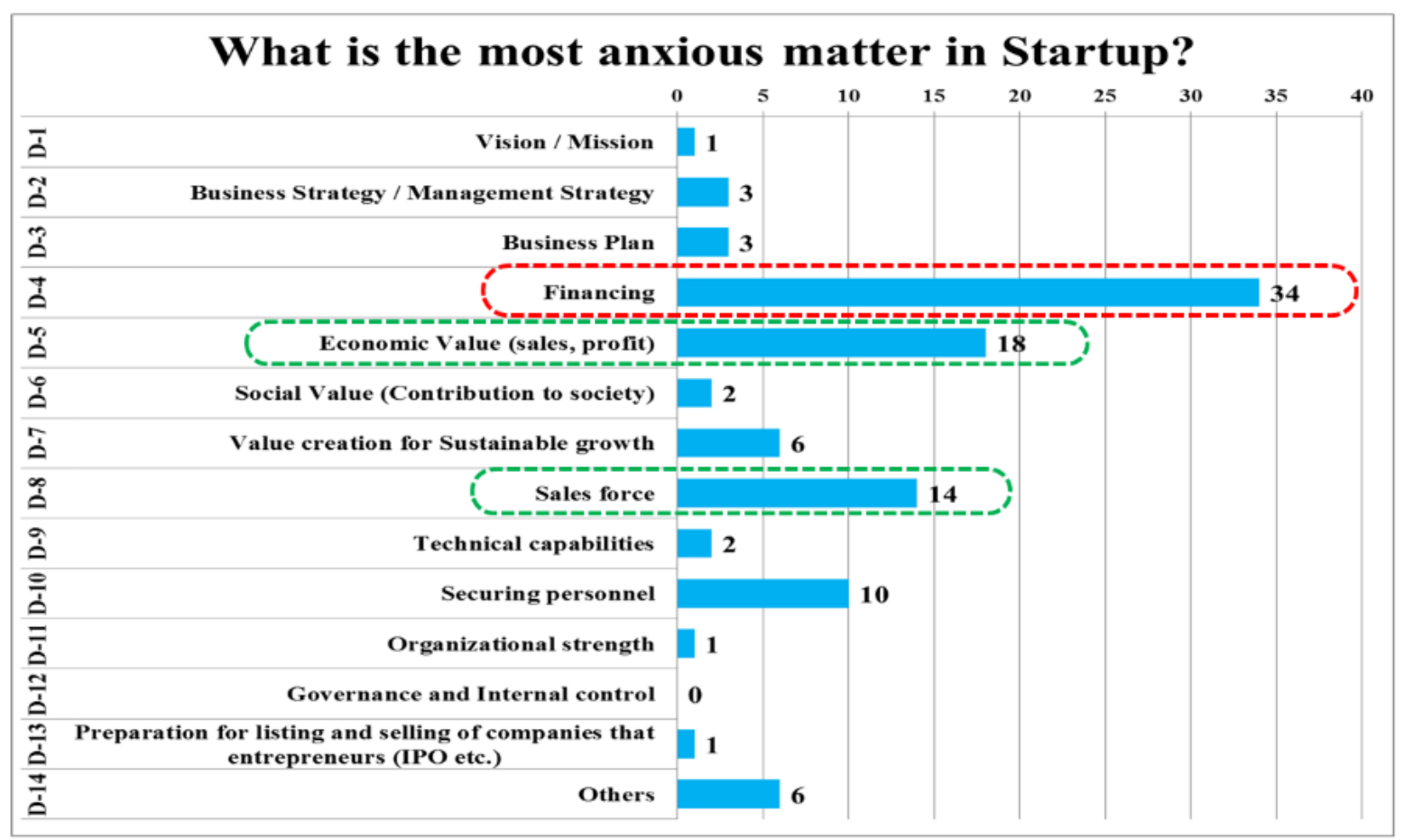

Figures. 18. What is the most anxious matter in Startup?

The correlation coefficient between each item is shown in Figure 19. The positive correlation coefficient with a correlation coefficient of 0.5 or more is as follows.

- Organizational strength / Securing personnel: 0.616

- Internal Governance and Control / Organizational Strength: 0.587

- Value creation for Sustainable growth / Social Value (Contribution to society): 0.583

At startup, the relationship between organizational capability and human resources, the relationship between governance, internal control and organizational capability is high, and the relationship between value creation for sustainable growth and social value is also considered high.

\section{Discussion}

In this chapter, we will consider the points that need to be emphasized during startup and the effectiveness of the Start-Up Management Knowledge Body (SUBOK) Guide.

According to the results of the start-up questionnaire, more than $90 \%$ of respondents believe that vision $/ \mathrm{mission}$, business strategy/management, business planning, economic value (sales, profit) and financing are important in start-ups. On the other hand, 80 respondents (74\%) said that emphasis should be placed on economic value and social value, indicating that there is significance in creating socially valuable projects in startups. Based on these results, in order to increase the probability of startup success and to achieve sustainable growth, we think it is effective to efficiently carry out management processes that create economic value and social value.

Therefore, from the process of six knowledge areas of the Start-Up Management Body of Knowledge Guide (SUBOK), we extract useful processes and tasks by applying project management methods and discuss how to use them. Each Start-Up Management Body of Knowledge Guide (SUBOK) process should be individually selected and adjusted as necessary at startup. Therefore, even in the application of project management methods, it is possible to further improve usability by adjusting the scope of coverage and the number and content of iterations according to the startup's goals, interests and priorities of needs, etc. 
In startups that are leveraging new technologies such as AI technology, IoT, Big data with rapid technological advancements, we respond flexibly to market needs and changing environments, provide products and services ahead of other companies, and besides flexibly and quickly deliver shipments across the globe. startup process Important to create and run. Therefore, in the management process below, we think it would be effective to use the Start-Up Management Body of Knowledge Guide (SUBOK) incorporating project management methods.

\subsection{Startup Strategy Management}

In the startup strategy management, there is a possibility that efficiency can be increased by utilizing the Start-Up Management Body of Knowledge (SUBOK) Guide in the following process. For example, when planning a business plan, lean canvas, SWOT analysis, BSC strategy map, etc. can be used. Figure 20 shows an example of a BSC strategy map.

- Formulation of commercialization plan in lean canvas etc. (Business discovery process and domain setup)

- Strategic priority checks and consensus building (startup strategy plan formulation process)

- Checking the concrete time schedule based on priority (roadmap formulation process)

\subsection{Startup Governance Management}

In startup governance management, the Body of Knowledge Guide (SUBOK) of Start-Up management is considered to be able to be utilized with the following process. In particular, CSV (Creating Shared Value), a management framework that tries to balance "social value" and "economic value" arising from solving social problems through corporate business, Although it can be considered as strategic management, but can also be considered as governance by including it in the code of ethics as a guideline for companies to fulfill their social responsibilities while realizing sustainable growth. Figure 21 illustrates the Code of Conduct.

In addition, in the Start-Up Management Body of Knowledge (SUBOK) Guidelines, companies adhere to the ten principles of the UN Global Compact (UNGC) and the SDG Compass (Corpse Code of Conduct) to achieve sustainable growth while fulfilling social responsibilities. It also introduces the CSV evaluation sheet.

- The process of review and consensus of ethical norms of behavior (process of formulating ethical norms of behavior)

- Study of the direction of governance management (governance management planning process)

- Review of social responsibility, Creating Shared Value (CSV) policies and consensus building (CSR policy formulation process)

\subsection{Startup Execution Integrated Management}

Startup Problems In integrated management, it is considered that the Body of Knowledge Guide (SUBOK) of Start-Up management can be utilized by the following process.

- Consideration and reconsideration of strategy review and change (change integration process)

- End startup activity assessment for company establishment (EXIT process of startup execution cycle)

\subsection{Startup Benefit Management}

In the startup benefit management, it is considered that the Start-Up management Body of Knowledge (SUBOK) Guide can be utilized by the following process.

- Identify values to initiate between stakeholders and form consensus (value definition process)

- Discussion and consensus building on value evaluation and change (value evaluation process)

\subsection{Startup Finance Management}

In the financial management of startups, it is considered that the Body of Knowledge Guide (SUBOK) of Start-Up management can be utilized with the following process. 
- Identification of options for procurement planning and procurement policy determination (process of creating an executable financial structure)

- Review of the status of the procurement of funds and changes in the method of procurement of funds (process of controlling the procurement of funds)

\subsection{Startup Finance Management}

In the management of startup organizations, it is considered that the Body of Knowledge Guide (SUBOK) of Start-Up management can be utilized by the following process.

- Examination of the ideal form of organization at startup and formation of consensus (startup organization design process)

- Consideration and confirmation of concrete organization structure and adoption (process of building startup organization)

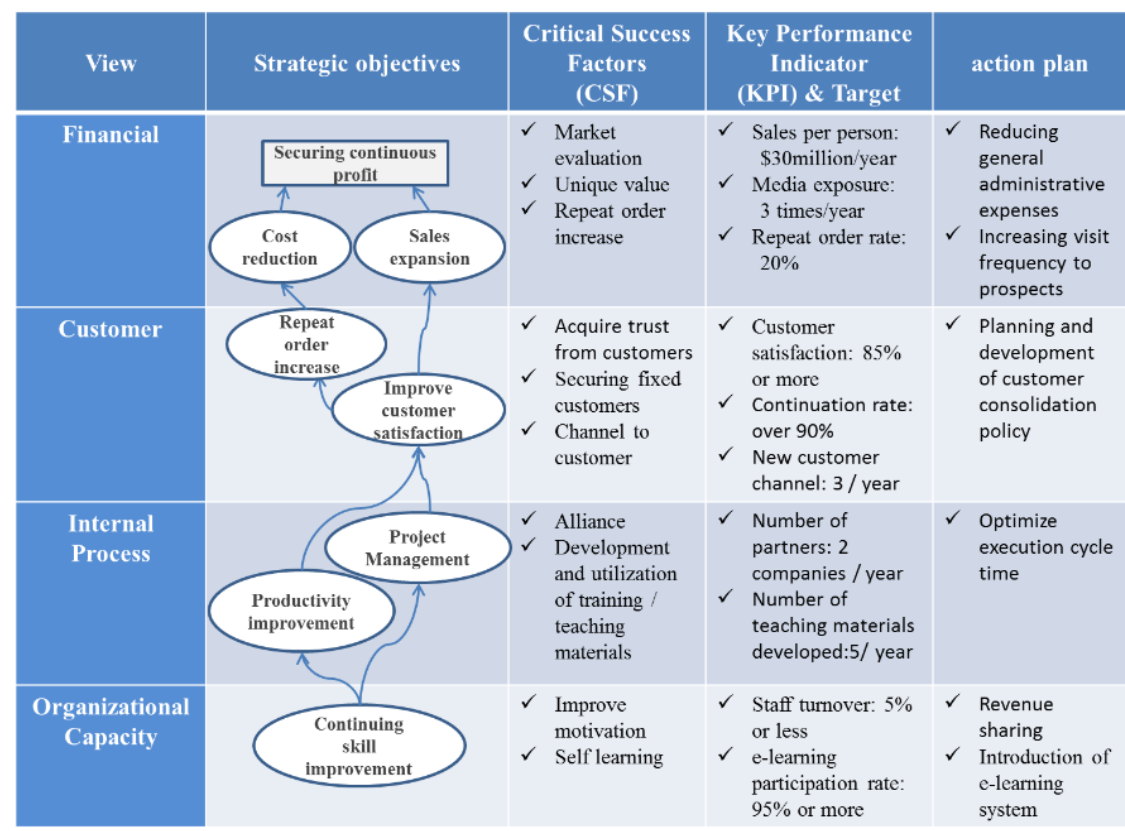

Figures. 20. Example of BSC Strategy Mapping 


\section{Respect for human rights}

We will respect human rights and do not discriminate. In addition, we will maintain and improve corporate vitality through human resource development and respect personality and personality of employees.

\section{- Purpose of corporate activities}

Through our business, we will work to improve corporate value, create and provide useful services / products with safety considerations, and strive to realize a rich society with both minds.

\section{- Fair and impartial corporate activities}

In the development of corporate activities, we comply with various laws, international agreements and company regulations and take responsible actions in line with social norms.

\section{- Management and disclosure of information}

In order to properly manage company information, gain correct understanding from society in general including stakeholders, and to maintain transparency, disclose information in a timely and appropriate manner.

\section{- Consideration for the global environment}

Based on the recognition that companies that are not concerned about the global environment can survive, we strive to preserve the global environment in all aspects of our corporate activities and aim for sustainable development.

\section{Social Contribution Activities}

As a member of society, actively contribute to society toward realizing a better society. We also support voluntary social contribution activities by employees.

Figures. 21. Example of Code of Conduct

\section{Discussion}

In this study, by conducting questionnaires on startups and analysis, it is important for startups to balance economic values and social values, in addition to business strategies and funding procurement which have been considered the most important. effective way to present the process to achieve it and consider the usefulness of implementing the Start-Up Management Body of Knowledge (SUBOK) Guide. In particular, recognizing the possibility that the Start-Up Management Body of Knowledge (SUBOK) Guide can contribute to certain efficiencies in running management processes at startups by implementing rapidly changing technologies. However, in order to create economic value and social value, which is one of the most important items in a startup, and to develop an effective methodology to deliver benefits to stakeholders, we need to delve deeper into that feeling.

This study discusses the usefulness of the Start-Up Management Body of Knowledge (SUBOK) Guide referring to the project management method. In the near future, we would also like to study social project management methods to realize social benefits which are considered to be one of the most important for making startups successful, and to advance the CSV strategy for creating economic and social value proposed by Michael Porter (2011).

\section{References}

[1] Cabinet Office Economic and Social Research Institute (2016). "Annual Estimates of National Accounts Calculated in FY2015 (revised 2011)" Cabinet Office.

[2] Global Entrepreneurship Research Association (2017).."Global Entrepreneurship Monitor Global Report 2016/17".Global Entrepreneurship Research Association, London Business School. 
[3] Ministry of Economy, Trade and Industry (Nomura Research Institute) (2016).."Investigation of entrepreneurship and venture support in FY2015".Ministry of Economy, Trade and Industry.

[4] Small and Medium Enterprises (2011)." White Paper for Small and Medium Enterprises (2011)" Small and Medium Enterprises.

[5] Small and Medium Enterprises (2017)."White Paper of Small and Medium Enterprises (2017)" Small and Medium Enterprises.

[6] Nomura Research Institute (2017)."IT Roadmap 2017 Edition -Through Predicting Technological Trends to Transform Business, Economy, and Society Work " Toyo Keizai Inc.

[7] Shogo Kamei, Masakazu Ohashi (2013)."Use of architectural connections and dynamics in small and medium-sized enterprises".Journal of the Infosocionomics Society 8(2).

[8] Bettina Bien Greaves (1998). "HUMAN ACTION: A Treatise on Economics". The Ludwig von Mises Institute.

[9] Takashi Umezu, Yumi Suzuki, Hitoshi Hirai, Satoshi Fujita, Hajime Fujito, Yasunori Miyazato/2017).

[10] Project Management Institute, Inc. (2013)."PMBOK®Guide 5th Edition (Project Management Knowledge Body Guide (PMBOK®Guide) Fifth Edition)" PMI

[11] Project Management Institute, Inc. (2016)."PMBOK®Guide 5th Edition Software Extension to PMBOK®Guide -Fifth Edition" PMI.

[12] TakashiUmezu, YumiSuzuki, HitoshiHirai, SatoshiFujita, HajimeFujito, Yasunori Miyazato (2017)."Development of Start-Up Management Knowledge Bodies Utilizing Project Management Techniques" National Institute of Advanced Industrial Science and Technology.

[13] Roi Shigematsu, Robert Hiroshi Mathis (2017) "Laws for building competitive advantage in the IoT ecosystem" DIAMOND Harvard Business Review (June 2017 issue).

[14] David J Collis(2016)."Combining strategy with lean startup" DIAMOND Harvard Business Review (August 2016 issue).

[15] Nestlé S.A., Public Affairs (2017)."Nestlé in society 2016" Nestlé S.A., Public Affairs.

[16] HirotoshiKamba (2017)."New wave of PM role models, how are you preparing?"PMI Japan Forum 2017 (8 July 2017 ). 